Center for

Ouantitative

Economics

\title{
Do Individual Index Futures Investors Destabilize the Underlying Spot Market?
}

Martin T. Bohl, Christian A. Salm and Bernd Wilfling ${ }^{\dagger}$

$6 / 2009$

${ }^{\dagger}$ Department of Economics, University of Münster, Germany

wissen.leben

WWU Münster 


\title{
Do Individual Index Futures Investors Destabilize the Underlying Spot Market?*
}

\author{
Martin T. Bohl ${ }^{\dagger}$ Christian A. Salm and Bernd Wilfling \\ Westfälische Wilhelms-University Münster, Germany
}

October 19, 2009

\begin{abstract}
This paper investigates the impact of introducing index futures trading on the volatility of the underlying stock market. We exploit a unique institutional setting in which presumably uninformed individuals are the dominant trader type in the futures markets. This enables us to investigate the destabilization hypothesis more accurately than previous studies do and to provide evidence for or against the influence of individuals trading in index futures on spot market volatility. To overcome econometric shortcomings of the existing literature we employ a Markov-switching-GARCH approach to endogenously identify distinct volatility regimes. Our empirical evidence for Poland surprisingly suggests that the introduction of index futures trading does not destabilize the spot market. This finding is robust across 3 stock market indices and is corroborated by further analysis of a control group.
\end{abstract}

JEL Classification: C32, G10, G14, G20

Keywords: Individual Investors, Uninformed Trading, Stock Index Futures, Emerging Capital Markets, Stock Market Volatility, Markov-Switching-GARCH Model

${ }^{*}$ The authors would like to thank Tino Berger, Ahmet Karagozoglu, Bernd Kempa, Emanuel Moench, Kate Phylaktis, Michael Schuppli, Maria Teresa Vespucci, participants of the research seminar at the Westfälische Wilhelms-University Münster, at the 43rd Euro Working Group on Financial Modelling meeting at Cass Business School (London), and at the 2009 meeting of the German Economic Association (Magdeburg).

${ }^{\dagger}$ Corresponding author: Martin T. Bohl, Department of Economics, Westfälische WilhelmsUniversity Münster, Am Stadtgraben 9, D-48143 Münster, Germany, Fax: +49-251-83-22846, Phone: +49-251-83-25005, E-mail address: martin.bohl@wiwi.uni-muenster.de. 


\title{
Do Individual Index Futures Investors Destabilize the Underlying Spot Market?
}

\begin{abstract}
This paper investigates the impact of introducing index futures trading on the volatility of the underlying stock market. We exploit a unique institutional setting in which presumably uninformed individuals are the dominant trader type in the futures markets. This enables us to investigate the destabilization hypothesis more accurately than previous studies do and to provide evidence for or against the influence of individuals trading in index futures on spot market volatility. To overcome econometric shortcomings of the existing literature we employ a Markov-switching-GARCH approach to endogenously identify distinct volatility regimes. Our empirical evidence for Poland surprisingly suggests that the introduction of index futures trading does not destabilize the spot market. This finding is robust across 3 stock market indices and is corroborated by further analysis of a control group.
\end{abstract}

JEL Classification: C32, G10, G14, G20

Keywords: Individual Investors, Uninformed Trading, Stock Index Futures, Emerging Capital Markets, Stock Market Volatility, Markov-Switching-GARCH Model 


\section{Introduction}

While it is well-established that futures markets are closely linked to the underlying spot markets through the process of arbitrage, two main lines of argument exist in the theoretical literature concerning the impact of introducing a futures market on underlying spot market volatility. On the one hand, futures trading destabilizes the underlying market by increasing stock market volatility due to the existence of uniformed investors. Attracted by high leverage badly informed investors induce noise in the price discovery process and lower the information content of prices. This implies higher spot market volatility as compared to the situation without a futures market (Cox, 1976; Cagan, 1981; Figlewski, 1981; Stein, 1987; Hart and Kreps, 1986). On the other hand, it is argued that futures markets have a stabilizing effect on the underlying spot market because futures trading improves price discovery, enhances market efficiency, increases market depth as well as information flows and contributes to market completion. As a result, the introduction of futures trading reduces the volatility of the underlying spot market (Powers, 1970; Danthine, 1978; Bray, 1981; Kyle, 1985; Stoll and Whaley, 1988).

Owing to this inconclusiveness, empirical investigations appear to be necessary in order to gain additional insight into the impact of futures trading on spot market volatility. While direct econometric tests of the theoretical approaches turn out to be infeasible, the empirical literature exploits the introduction of futures markets to quantify the effect on spot returns volatility. The majority of these recent time series investigations share at least two common characteristics (Antoniou et al., 1998; Gulen and Mayhew, 2000; McKenzie et al., 2001; Antoniou et al., 2005): First, the studies implement GARCH-type models augmented by dummy variables. These dummy variables allow the authors to discriminate between the pre- and the post-futures period and thus to analyze the impact that the introduction of index futures markets has on spot market returns volatility. Second, the available studies provide empirical evidence primarily for mature stock markets in which institutional investors constitute the predominant trader type. 
The first characteristic can be challenged since the dummy variable approach relies on an exogenous determination of the shift in stock returns volatility. Moreover, this simple technique only models an abrupt one-step change in the volatility process which does not constitute a realistic pattern of volatility changes. It rather turns out to be more appropriate to model the shift in stock returns volatility endogenously and to let the data speak for themselves. By construction, the one-step dummy variable approach cannot capture a gradual adjustment to a new volatility regime and does not allow for a transitory volatility change.

With respect to the second characteristic mentioned above index futures markets in mature countries were mainly introduced in the 1980s at the time when institutional investors were the dominant players in stock markets. Typically, financial economists tend to regard institutional investors as informed traders while individual investors are considered as uninformed (for example, Lee et al., 1999; Cohen et al., 2002; Barber and Odean, 2008; Kaniel et al., 2008). Therefore, the characteristic of futures markets being mainly populated by informed investors comes into conflict with the destabilization hypothesis according to which uninformed investors induce noise in the price discovery process and lower the information content of prices. Consequently, a valid empirical approach should make use of an institutional framework in which uninformed investors play a dominant role.

In this paper, we take into account the two aspects outlined above. Instead of a simple dummy variable approach we implement a Markov-switching-GARCH model that has recently emerged in the finance literature. This econometric technique provides empirical and graphic evidence of whether and of how the introduction of a futures market changes the volatility structure of stock returns in the underlying spot market. It allows for endogenous volatility regime shifts and reveals if the volatility structure has changed transitorily or permanently.

Moreover, we exploit a unique institutional characteristic of the index futures market in Poland which is in closer line with the destabilization hypothesis. In terms of trading turnover individual investors in the Polish futures market accounted for more than $80 \%$ during the first five years after the start of the futures market (1998 - 2002) and 
around $75 \%$ during the following three years (2003 - 2005). Across recent years (2006 - 2007) individual investors' proportion of trading volume is still well above $55 \%$. It is precisely this dominance of presumably uninformed individual traders in the Polish futures markets which enables us to investigate the destabilization hypothesis more accurately than previous studies do. If the destabilization hypothesis is valid and if individual investors are uninformed traders, our findings for the Polish stock market should provide clear-cut evidence in favour of a permanent increase in stock market volatility after the introduction of the index futures market segment. Our empirical evidence for Poland suggests that the introduction of index futures trading does not destabilize the spot market. Furthermore, no evidence for stabilizing effects appears, therefore the introduction of index futures trading does not seem to influence the volatility of the underlying spot market. This finding is robust across 3 stock market indices and consistent with results from a control group.

Our paper contributes to the voluminous literature on the impact of futures markets on the underlying spot market. Recent studies explicitly elaborate the importance of the investor structure and, in particular, the role of individual investors. McMillan and Garcia (2008) investigate the impact of introducing the mini-futures contract for the Spanish Ibex index in November 2001 on overall market efficiency. The main purpose of this contract was to stimulate individual traders' access to futures markets. However, the mini-futures contract has entailed greater noise in the dynamic relationship between spot and futures markets. Kurov (2008) analyzes the US S\&P 500 and Nasdaq-100 E-mini futures in order to examine whether futures traders exhibit feedback trading strategies. The median trade size in both market segments is consistent with small individual traders accounting for a substantial proportion of trading. The empirical findings for both types of E-mini futures show that investors are positive feedback traders who buy after price increases and sell after price declines.

Also related to our study is the work of Bae et al. (2004) who analyze the effect of introducing the KOSPI 200 index futures trading in South Korea in May 1996 on returns volatility and market efficiency. Among other peculiarities in the KOSPI 200 futures market individual investors account for about $40 \%$ of the trading volume. Bae 
et al.'s results indicate that stock returns volatility and market efficiency increase. However, when compared to non-KOSPI 200 stocks, KOSPI 200 stocks show lower returns volatility after the introduction of futures trading.

It is important to note that none of the studies just mentioned makes use of an econometric technique which allows for endogenously determined volatility regime shifts and a market setting with individual investors as the by far dominant investor group. The key innovation of our paper therefore is to overcome this empirical lack by applying a Markov-switching-GARCH model to Polish index futures traded in a market heavily dominated by individual investors.

The remainder of the paper is organized as follows. Section 2 describes the institutional background of the Polish spot and index futures markets. Section 3 presents the data set and develops our Markov-switching-GARCH methodology. Section 4 discusses the empirical results. Section 5 summarizes and offers some concluding comments.

\section{The Polish spot and index futures markets}

The first stock exchange in Warsaw was founded in 1817. Having been closed during World War II and the communist era, the Polish stock market was reopened on 16 April 1991. Since the first session the WIG index has been calculated and comprises all companies listed at Warsaw Stock Exchange (WSE) that meet base eligibility criteria. ${ }^{1}$ Exactly three years later, the WIG20 stock price index was launched. This index reflects the performance of 20 blue chip stocks listed on the main market of the WSE. The sWIG80 (called WIRR until 16 March 2007) price index has been calculated since 31 December 1994 and comprises 80 smaller companies listed at the WSE. The mWIG40 (called MIDWIG until 16 March 2007), a mid-cap price index, followed on 21 September 1998, and the TechWIG price index, representing innovative technologies, on 31 December 1999.

Being a medium-size stock exchange in Europe, the WSE ranks first in market capitalisation among the exchanges in all Central and Eastern European (CEE) countries.

\footnotetext{
${ }^{1}$ All information about the WSE is taken from the annual fact books. The comparisons of the WSE with other exchanges are based on the World Federation of Exchanges Annual Report 2007.
} 
As of 2007, the total market capitalization of the WSE has reached USD 212 billion, which is far higher than the capitalization of other CEE countries markets like Budapest (USD 46 billion) and Prague (USD 70 billion). In fact, its size rivals that of smaller Western European exchanges such as Vienna (USD 236 billion) or Luxembourg (USD 166 billion). The Polish stock market has been growing rapidly in part because formerly state-owned companies were privatised and listed on the WSE. The first foreign company (Bank Austria Creditanstalt AG) was listed at the WSE on 14 October 2003. Since 1 May 2004, the exchange's market structure has been complying with EU standards, i.e. securities trading has two segments, namely the main market and the regulated unofficial parallel market.

Initially, there was a spot market only. Futures contracts on the WIG20 have been traded at the WSE since 16 January 1998. This was the first derivative product introduced by the exchange. It became quickly popular among Polish investors. On 1 August 2000, futures contracts on the TechWIG index were introduced, with contracts on the mWIG40 index following on 18 February 2002. ${ }^{2}$ Since 1998 the index futures market in Poland has grown substantially as Figure 1 illustrates in terms of trading volume at the WSE.

[Insert Figure 1 about here]

With a volume of 9.36 million contracts traded and a notional value of USD 122,191 million, total index futures trading at the WSE in 2007 is comparable in volume to trading at Western European markets such as at the Borsa Italia (6.74 million contracts; USD 1,428,831 million) or at the Spanish MEFF (11.30 million contracts; USD 1,774,694 million). At the same time, the Polish stock index futures market is considerably larger compared to those of other CEE countries, as for instance that of Budapest

\footnotetext{
${ }^{2}$ For completeness: Futures contracts on individual stocks were first launched on 22 January 2001. Put and call options with the WIG20 as underlying were introduced on 22 September 2003, and on individual stocks started trading on 17 October 2005. Moreover, trading has been suspended in futures on three individual stocks. Futures contracts on USD debuted on 25 September 1998, followed by futures on the Euro on 1 May 1999. T-note futures were launched on 14 February 2005. Ordinary warrants started trading on 9 March 1998, with American-style warrants on WIG20 futures contracts joining in on 24 September 2001.
} 
(3.95 million contracts; USD 5,758 million) and even those of some Western European exchanges such as Athens (2.74 million contracts; USD 52,096 million) and Vienna (0.23 million contracts; USD 21,561 million).

Trading on the spot and derivatives market takes place on the continuous trading system of the WSE. ${ }^{3}$ The futures contracts expire in March, June, September, and December. The last trading day of any given contract is the third Friday of its expiry month, or the last trading day prior to that Friday in case of public holidays.

More relevant to our field of research is the unique investor structure on the Polish futures market. Figure 2 exhibits all details on the investor structure between 1997 and 2007. On the futures markets, individual investors are the dominating trader type accounting for about $75 \%$ of the turnover value on average over the past 9 years, with domestic institutions contributing $20 \%$ while the remaining $5 \%$ were allocated to foreign investors. During the last 11 years, the spot turnover shares of domestic private, domestic institutional and foreign investors have remained relatively equal.

[Insert Figure 2 about here]

This dominance of individual investors on the futures market is mainly due to three factors: First, small transactions can be settled in the Polish derivatives market. For example, the value of an index futures contract equals the product of the multiplier and the price of the underlying. The former was set to only $10 \mathrm{zl}$ the current value of which is about USD 2.75. This small multiplier makes index futures affordable for small investors. Second, individual investors who wish to trade in the Polish futures market can easily register to do so without formal barriers. Third, major Polish institutional investors are not permitted to trade in derivatives. Polish pension funds are not allowed

\footnotetext{
${ }^{3}$ The trading hours of the continuous trading system were $12.00 \mathrm{am}$ to $4.00 \mathrm{pm}$ on the spot and $10.15 \mathrm{am}$ to $4.00 \mathrm{pm}$ on the derivatives market prior to the introduction of the quotation system WARSET on 17 November 2000. Thereafter, stocks were traded continuously from $10.00 \mathrm{am}$ to $4.10 \mathrm{pm}$ and derivatives from $9.00 \mathrm{am}$ to $4.10 \mathrm{pm}$. For both markets, an auction is held at opening and closing of the session. On 1 September 2003, the WSE has introduced a 10-minute post-auction phase for spot and derivatives trading, which follows the closing auction at 4.10pm. Since 3 October 2005, the continuous trading on the spot market started 30 minutes earlier at 9.30am and closing auctions on spot and derivatives markets were held at $4.20 \mathrm{pm}$, i.e. 10 minutes later than before. On 1 September 2008 , the WSE trading hours were further extended. After this, trading sessions on the spot market began at $9.00 \mathrm{am}$ and sessions on the derivatives market started at 8.30am.
} 
to invest in derivatives. Originally, domestic mutual funds were also not authorized to place investments into derivatives. A change in legislation, i.e. a new Act of Investment Funds coming into effect in the Fall of 2004, opened the index futures market to this class of institutional investors.

\section{Data and econometric technique}

Our data set consists of daily close prices of the WIG20, the TechWIG and the mWIG40 stock price indices. To allow for comparison to be made between these three market indices and markets which are not underlying any futures contracts, we also include daily close prices of the WIG and sWIG80 index to our data set. The WIG and sWIG80 index act as a control group to the other three market indices. The WIG index comprises all companies listed at the WSE, including the ones contained in the WIG20, the TechWIG and the mWIG40 indices. This might weaken its quality as a clear-cut control variable. Therefore, the control group also contains the sWIG80 index which excludes completely WIG20 and mWIG40 index participants, but includes some of the stocks contained in the TechWIG. Furthermore, in order to control for the interdependence of the Polish stock market with the international stock market, we employ daily close prices of the S\&P500 index. The time series for the WIG20, the TechWIG, the mWIG40, the WIG, and the sWIG80 were all obtained from the WSE while the S\&P500 index data were compiled from Thomson Reuters Datastream.

The sample periods run from 1 November 1994 to 31 December 2007 for the WIG20 and the WIG (3292 trading days), from 31 December 1994 to 31 December 2007 for the sWIG80 (3253 trading days), from 31 December 1999 to 31 December 2007 for the TechWIG (2006 trading days), and from 21 September 1998 to 31 December 2007 for the mWIG40 (2505 trading days). ${ }^{4}$ The sample period ends on 31 December 2007 to obtain a data set under similar conditions regarding the investor structure. At the WSE futures market, in 2008 and 2009 the share of trading volume attributable to domestic institutional investors has further increased which erodes our testing basis of

\footnotetext{
${ }^{4}$ The WSE has back-calculated the TechWIG price index, which was introduced on 19 May 2000, to 31 December 1999.
} 
an extraordinarily high proportion of individual investors. Part of the observed shift in the investor structure can be rationalized by changes in the regulatory framework of the Polish financial market. ${ }^{5}$ For each index used in our econometric analysis below, we define the daily return as $R_{t} \equiv 100 \cdot\left[\ln \left(\operatorname{Index}_{t}\right)-\ln \left(\operatorname{Index}_{t-1}\right)\right]$.

In order to model endogenous volatility shifts in our index return time series $\left\{R_{t}\right\}$, we make use of a Markov-switching-GARCH model as developed in Gray (1996b) and recently refined in Wilfling (2009) and Gelman and Wilfling (2009). The general idea behind this econometric framework is that the data generating process (DGP) of the return $R_{t}$ is affected by a latent random variable which represents the state the DGP is in on any particular date $t$. In our analysis we denote this latent state variable by $S_{t}$ and use it to discriminate between two distinct volatility regimes. We specify $S_{t}=1$ to indicate that the DGP is in the high-volatility regime whereas $S_{t}=2$ is meant to indicate that the DGP is in the low-volatility regime.

The basic element of our Markov-switching-GARCH model is the well-known probability density function of a mean-shifted $t$-distribution with $\nu$ degrees of freedom, mean $\mu$ and variance $h, t_{\nu, \mu, h}$. Based on this parametric density function, our next step will consist in specifying stochastic processes for the mean and the volatility in regime $i$, denoted by $\mu_{i t}$ and $h_{i t}$, according to which the stock return $R_{t}$ is generated conditional upon the regime indicator $S_{t}=i, i=1,2$. After having specified $\mu_{i t}$ and $h_{i t}$ we can then represent the conditional distribution of the stock return as a mixture of two mean-shifted $t$-distributions:

$$
R_{t} \mid \phi_{t-1} \sim\left\{\begin{array}{ll}
t_{\nu_{1}, \mu_{1 t}, h_{1 t}} & \text { with probability } p_{1 t} \\
t_{\nu_{2}, \mu_{2 t}, h_{2 t}} & \text { with probability }\left(1-p_{1 t}\right)
\end{array},\right.
$$

where $\phi_{t-1}$ defines the information set as of date $t-1$ and $p_{1 t} \equiv \operatorname{Pr}\left\{S_{t}=1 \mid \phi_{t-1}\right\}$ denotes the so-called ex-ante probability of being in regime 1 at time $t$.

In modeling our regime-dependent mean equation, we explicitly take into account the possibility of first-order autocorrelation in index returns and the interdependence

\footnotetext{
${ }^{5}$ A new Act of Investment Funds coming into effect in the Fall of 2004, opened the index futures market to mutual funds. At the same time, a generally more liberal mutual fund regulation policy triggered a rapid growth of the number of mutual funds in the Polish market, beginning only in the following year of 2005. Moreover, the new Act allowed foreign investment funds to operate directly in the Polish market. These institutional changes triggered a massive growth of mutual funds in Poland.
} 
of the Polish stock market with the international stock market. We meet both aspects by including $R_{t-1}$ and the lagged S\&P500 index return $R_{t-1}^{\mathrm{SP}}$ as a control variable in our mean equation:

$$
\mu_{i t}=a_{0 i}+a_{1 i} R_{t-1}+a_{2 i} R_{t-1}^{\mathrm{SP}} \quad \text { for } i=1,2 .
$$

In contrast to the mean equation (2), the specification of an adequate GARCH process for the regime-specific variance $h_{i t}$ is more problematic. Without going into technical detail, we first consider an aggregate of conditional stock index-return variances from both regimes at date $t:^{6}$

$$
\begin{aligned}
h_{t} & =E\left[R_{t}^{2} \mid \phi_{t-1}\right]-\left\{E\left[R_{t} \mid \phi_{t-1}\right]\right\}^{2} \\
& =p_{1 t}\left(\mu_{1 t}^{2}+h_{1 t}\right)+\left(1-p_{1 t}\right) \cdot\left(\mu_{2 t}^{2}+h_{2 t}\right)-\left[p_{1 t} \mu_{1 t}+\left(1-p_{1 t}\right) \mu_{2 t}\right]^{2} .
\end{aligned}
$$

The quantity $h_{t}$ now provides the basis for the specification of the regime-specific conditional variances $h_{i t+1}, i=1,2$ in the form of a parsimonious $\operatorname{GARCH}(1,1)$-structure. More explicitly, we follow the suggestion of Dueker (1997) and first parameterize the degrees of freedom of the $t_{\nu, \mu, h}$-distribution by $q=1 / \nu$, so that $(1-2 q)=(\nu-2) / \nu$, and then specify our regime-specific GARCH equation as:

$$
h_{i t}=b_{0 i}+b_{1 i}\left(1-2 q_{i}\right) \epsilon_{t-1}^{2}+b_{2 i} h_{t-1}
$$

with $h_{t-1}$ as being given according to Eq. (3) and $\epsilon_{t-1}$ being obtained from:

$$
\begin{aligned}
\epsilon_{t-1} & =R_{t-1}-E\left[R_{t-1} \mid \phi_{t-2}\right] \\
& =R_{t-1}-\left[p_{1 t-1} \mu_{1 t-1}+\left(1-p_{1 t-1}\right) \mu_{2 t-1}\right] .
\end{aligned}
$$

It is important to note here that for $i=1,2$ the sums $b_{1 i}\left(1-2 q_{i}\right)+b_{2 i}$ of the coefficients from Eq. (4) constitute convenient measures of the regime-specific persistence of volatility shocks. The higher the value of this measure the more time it takes until a shock dies out. A regime-specific volatility shock will die out in finite time if the coefficient sum is less than 1 . For the case of the coefficient sum being equal to 1

\footnotetext{
${ }^{6}$ See Gray (1996b) for a rigorous formal discussion.
} 
(i.e. for an integrated $\operatorname{GARCH}(1,1)$ process) volatility shocks have a permanent effect and the unconditional variance of the process becomes infinitely large.

Finally, we close our Markov-switching-GARCH model by parameterizing the regime indicator $S_{t}$ as a first-order Markov process with constant transition probabilities. Denoting by $\pi_{i}$ the probability of the DGP persisting in regime $i$ (for $i=1,2$ ) between the dates $t-1$ and $t$, we specify:

$$
\begin{array}{ll}
\operatorname{Pr}\left\{S_{t}=1 \mid S_{t-1}=1\right\}=\pi_{1}, & \operatorname{Pr}\left\{S_{t}=2 \mid S_{t-1}=1\right\}=1-\pi_{1}, \\
\operatorname{Pr}\left\{S_{t}=2 \mid S_{t-1}=2\right\}=\pi_{2}, & \operatorname{Pr}\left\{S_{t}=1 \mid S_{t-1}=2\right\}=1-\pi_{2} .
\end{array}
$$

Now, the log-likelihood function of our Markov-switching-GARCH(1,1) model can be obtained by performing similar calculations as in Gray (1996b). The exact form of the function is presented in Wilfling (2009). The log-likelihood function contains the ex-ante probabilities $p_{1 t} \equiv \operatorname{Pr}\left\{S_{t}=1 \mid \phi_{t-1}\right\}$ which can be estimated via a recursive scheme. These probabilities are useful in forecasting one-step-ahead regimes based on an information set that evolves over time. In our context, the ex-ante probabilities $p_{1 t}$ reflect current market perceptions of the one-step-ahead volatility regime, thus representing an adequate measure of stock market volatility sentiments. Besides the $e x$ ante probabilities $p_{1 t}$ we also address the so-called smoothed probabilities $\operatorname{Pr}\left\{S_{t}=1 \mid \phi_{T}\right\}$ which can be computed by the use of filter techniques after the model estimation has been carried out. ${ }^{7}$ The smoothed probabilities are based on the full sample-information set $\phi_{T}$ and provide a tool for inferring ex post if and when volatility regime switches have occurred in the sample.

\section{Empirical results}

Table I presents the maximum-likelihood estimates of the Markov-switching-GARCH model for the WIG20, the TechWIG and the mWIG40 stock index returns. Maximization of the log-likelihood function was performed by the 'MAXIMIZE'-routine

\footnotetext{
${ }^{7}$ In this paper, we have computed all smoothed probabilities with a filter algorithm provided by Gray (1996a).
} 
within the software package RATS 7.1 using the BFGS-algorithm, heteroscedasticityconsistent estimates of standard errors and suitably chosen starting values for all parameters involved. Overall, the majority of the coefficients in the mean and GARCH equations (2) and (4) are statistically significant at the $1 \%$ level for all index return time series. ${ }^{8}$

[Insert Table I about here]

4 of the 6 autoregressive coefficients $a_{11}$ and $a_{12}$ are statistically significant and positive. A positive first-order autoregressive structure in stock index returns is an empirical finding often reported in the literature that can be explained by non-synchronous trading (Lo and MacKinlay, 1990), time-varying expected returns (Conrad and Kaul, 1988), transaction costs (Mech, 1993) and feedback trading (Shiller, 1989; Sentana and Wadhwani, 1992). The TechWIG exhibits a significant negative autoregressive coefficient $a_{11}$, while $a_{11}$ is not significant for the WIG20 and the mWIG40. For all 3 stock market indices the coefficients $a_{21}$ and $a_{22}$ of the lagged S\&P500 index returns $R_{t-1}^{S P}$ are statistically significant at the $1 \%$ level and positive in both regimes indicating strong interdependence between US and Polish stock markets.

Analyzing the estimated GARCH parameters, we find that the coefficient sums $b_{1 i}\left(1-2 q_{i}\right)+b_{2 i}$ are less than 1 for all stock return time series across both regimes. This result suggests that we have stationary conditional volatility processes in all regimes and implies that volatility shocks die out in finite time. The estimates of the transition probabilities $\pi_{1}$ and $\pi_{2}$ are all close to 1 indicating a high degree of regime persistence.

The lower part of Table 1 contains a diagnostic check of the model fit by providing Ljung-Box Q-statistics for serial correlation of the squared standardized residuals for the lags 1,2, 3, 5, and 10. For the TechWIG and the mWIG40 the null hypothesis

\footnotetext{
${ }^{8}$ Some comments on the probability distribution of the conventional $t$-statistic within our Markovswitching-GARCH framework are in order. It has to be noted that the exact finite-sample distribution of our $t$-statistics is generally unknown. However, owing to some well-known asymptotic properties of general maximum likelihood estimators in conjunction with an appropriate limiting distribution result, it can be concluded that under the null hypothesis of a single parameter being equal to zero, our $t$ statistics should converge in distribution towards a standard normal variate. This implies asymptotic critical values of $2.58,1.96$ and 1.64 for the absolute value of the $t$-statistic at the $1 \%, 5 \%$ and $10 \%$-levels, respectively.
} 
of no autocorrelation cannot be rejected up to lag 10 at any conventional significance level. This result provides some evidence in favour of our two-regime Markov-switchingGARCH specification. By contrast, for the WIG20 the Ljung-Box tests indicate serial correlation for the lags 1, 2, and 3. This finding is caused by two extreme daily WIG20returns recorded on the 28th and 29th October 1997 during the Asian crisis. Since the removal of these extreme stock returns from the data set eliminates all serial correlation while leaving the estimation results (not shown, but available upon request) unaffected, we decided to retain the observations in the sample.

Next, we address the ex-ante and the smoothed probabilities $\operatorname{Pr}\left\{S_{t}=1 \mid \phi_{t-1}\right\}$ and $\operatorname{Pr}\left\{S_{t}=1 \mid \phi_{T}\right\}$ both of which are relevant to detecting how often and at which dates the Polish stock market switched between the high-volatility and the low-volatility regimes. Figures 3, 4, and 5 display these regime-1 probabilities (in the upper panels) along with the conditional variance processes (in the lower panels) estimated from the Markov-switching-GARCH models for the WIG20, the TechWIG, and the mWIG40 index returns. Since the ex-ante probabilities are determined on the basis of an evolving (and thus smaller) information set, they exhibit a more erratic dynamic behaviour than the smoothed regime- 1 probabilities. In all panels the time period after the introduction of index futures trading is marked by grey shading. In all figures periods of high probabilities are associated with periods of high conditional volatility indicating that regime 1 is the high-volatility regime.

[Insert Figures 3, 4, and 5 about here]

According to the destabilization hypothesis, uninformed investors induce noise in the price discovery process and lower the information content of prices. As described in Section 2, individual and thus presumably uninformed investors are the dominant trader type in Polish index futures markets. If the destabilization hypothesis is valid and if individual investors are uninformed traders, we should see a clear-cut permanent increase in stock market volatility after the introduction of futures trading. As a result, in terms of our Markov-switching-GARCH approach, the spot market returns should perform a sustained switch to the high-volatility regime along with a higher conditional 
variance after the introduction of the futures market.

Looking at Figures 3, 4, and 5, for the most part, the evolution of the regime-1 probabilities and the conditional variance exhibit similar patterns for all three index returns. For the WIG20 a period of high volatility begins around February 1997 and ends in May 1999. After about 6 months of low stock market volatility a regime-switch to the high-volatility regime takes place at the beginning of 2000. This interval of high volatility ends in the second half of 2001. Besides some minor spikes in the regime1 probabilities and the conditional variance in the years 2006 and 2007, the WIG20 remains in the low-volatility regime until the end of the sample period. The TechWIG index starts in the high-volatility regime in January 2000. Comparable to the pattern observed for the second period of high volatility for the WIG20, a gradual transition towards the low-volatility regime occurs in the first half of 2001. The TechWIG index return process continues in the low-volatility regime and shows one temporary increase in volatility at the end of 2007 .

Three periods of high volatility emerge for the mWIG40 index. The mid-cap index begins in a period of high volatility in September 1998. The regime-1 probabilities and the conditional variance for the mWIG40 indicate a period in the low-volatility regime from the middle to the end of 2000. During the same time period, a temporary phase of low stock market volatility is also present in the WIG20 index process. From January 2000 until the end of the year, with a short interruption, the mWIG40 index switches to the high-volatility regime. Also the WIG20 and TechWIG progress in high-volatility regimes during this time period. In contrast to the evolution of the regime-1 probabilities of the WIG20 and TechWIG index the mWIG40 index switches to the high-volatility regime at the end of 2005 until mid-2007. But on average, the conditional volatility of the mWIG40 during this time period is considerably below the levels of the years 1998 and 1999 .

Most importantly, Figures 3, 4, and 5 demonstrate the impact of WIG20, TechWIG, and mWIG40 index futures trading on the conditional volatility of the underlying stock market index. The introduction of WIG20 index futures on the 16 January 1998 falls into the high-volatility regime. The temporarily lower volatility from mid- 
1999 to 2000 provides evidence against a sustained switch to the high-volatility regime after the introduction of the futures market which should be observed according to the destabilization hypothesis. Afterwards, from mid-2001 to the end of the sample period, the WIG20 persistently remains in the low-volatility regime.

8 months after the introduction of TechWIG futures trading on 1 August 2000, around April 2001, a gradual transition towards the low-volatility regime occurs for the underlying TechWIG spot market returns. Once again, this empirical finding does not reveal an increase in stock market volatility after the introduction of futures trading. The mWIG40 process remains in the low-volatility regime for 3.5 years after the introduction of index futures trading on 18 February 2002. There is a period of high volatility from the end of 2005 until mid-2007 after the introduction of index futures on the mWIG40 which occurs with a very long lag after the event. Furthermore, it is a temporary period of high volatility only and the levels of the conditional variance are relatively low as compared to the high-volatility regime in 1998-1999.

Summing up, for all three indices, the introduction of index futures does not lead to a transition to a high-volatility regime along with a higher conditional variance after the futures market introduction. Furthermore, there is no evidence for stabilizing effects. Thus the introduction of index futures trading does not seem to be connected with the volatility of the underlying spot market.

To gain further insights into the possibly destabilizing effect of futures trading on spot price volatility, we investigate the spot market returns for the WIG and the sWIG80 index. Futures contracts are not traded on the WIG and the sWIG80 index so that the two indices act as a control group. In contrast to the WIG index, the sWIG80 fully excludes WIG20 and mWIG40 index participants and to most parts stocks contained in the TechWIG. Therefore, the sWIG80 should further strengthen the reliability of our control group. If the destabilizing hypothesis is correct we expect a pattern of regime-1 probabilities and conditional variances that differs from the other indices for which a futures market has been introduced. Figures 6 and 7 display the regime-1 probabilities (in the upper panels) along with the conditional variance processes (in the lower panels) estimated from the Markov-switching-GARCH models for the WIG, and the sWIG80 
index returns. ${ }^{9}$ For the most part, the evolution of the regime-1 probabilities and the conditional variances of the WIG and the sWIG80 index exhibits a similar pattern than that of the other 3 index returns. Therefore, we conclude that, instead of being governed by index futures trading, the observed switches to high-volatility periods are more likely to have been caused by other events.

\section{[Insert Figures 6 and 7 about here]}

After a period of low conditional volatility we observe a jump to the high-volatility regime around February 1997 when all blue chip stocks contained in the WIG20 became continuously tradable. The first major unstable interval from October 1997 to May 1999 may have been induced by a sequence of crises with worldwide impacts on financial markets. The high volatile stock market after the end of 1997, around mid-1998 and after the beginning of 1999 may be associated with the Asian (October/November 1997), the Russian (August/September 1998) and the Brazilian (January 1999) crises. The second period (March 2000 to April 2001) in the high-volatility regime can be related to the worldwide bear market following the burst of the 'dot-com bubble'.

Combining the evidence from Figures 3,4 and 5 with that from Figures 6 and 7, the overall result is that the introduction of index futures trading in Poland does not destabilize the underlying cash markets. The observed switches between volatility regimes have not been caused by index futures trading, but rather appear to have been driven by other events such as financial turmoil. This result is inconsistent with the hypothesis that the Polish index futures market should have increased spot market volatility. The evidence is even more compelling given the specific investor structure of the Polish futures market where presumably uninformed individuals are the dominant trader type.

\footnotetext{
${ }^{9}$ Estimates of the Markov-switching-GARCH model for the WIG and the sWIG80 index returns are not reported but are available on request.
} 


\section{Summary and conclusions}

The aim of this paper is to investigate the impact of the introduction of index futures trading in Poland on the conditional return volatility of the underlying stock index markets. The Polish index futures market is dominated by individual investors, which are presumably uninformed. This unique institutional peculiarity of the index futures market in Poland enables us to investigate the destabilization hypothesis more accuratley than available studies do. To overcome econometric shortcomings of the existing literature we employ a Markov-switching-GARCH approach to endogenously identify distinct volatility regimes.

After examining the evidence, we conclude that the introduction of index futures trading in Poland does not lead to an increase in volatility of the underlying stock market. Consequently, we reject the destabilizing hypothesis. Furthermore, index futures trading does not seem to influence spot market volatility at all. The observed switches between volatility regimes in index returns may be explained by other events such as financial turmoil.

Our empirical investigation allows us to draw two major conclusions. First, we exploit a unique institutional setting in which individuals are the dominant trader type in the futures markets. Owing to this market structure, our empricial findings rely on a data basis with a presumably high noise proportion in the index futures market which may have transmitted to the underlying spot market via arbitrage links. However, the introduction of index futures trading in Poland does not lead to an increase in volatility of the underlying stock market. Therefore, we generally question whether the destabilizing hypothesis typically raised in the literature is a valid hypothesis on the impact of index futures trading on the underlying spot pricing process.

Second, we cast doubt on conclusions drawn from the empirical evidence in the available literature which implements GARCH-type models augmented by dummy variables. By construction, the one-step dummy variable approach cannot capture a gradual adjustment to a new volatility regime and does not allow for a transitory volatility change. In this paper, we employ a Markov-switching-GARCH approach which allows for en- 
dogenous volatility regime shifts and reveals if the volatility structure has changed transitorily or permanently. Using data from Poland, we are able to identify distinct non-permanent volatility regimes that do not seem to be governed by index futures trading. This precise identification could not have been achieved by a simple dummy variable approach. 


\section{References}

Antoniou, A., P. Holmes, and R. Priestley (1998). The effects of stock index futures trading on stock index volatility: An analysis of the asymmetric response of volatility to news. Journal of Futures Markets, 18, 151-166.

Antoniou, A., G. Koutmos, and A. Pericli (2005). Index futures and positive feedback trading: Evidence from major stock exchanges. Journal of Empirical Finance, 12, 219-238.

Bae, S.C., T.H. Kwon, and J.W. Park (2004). Futures trading, spot market volatility, and market effciency: The case of the Korean index futures markets. Journal of Futures Markets, 24, 1195-1228.

Barber, B. M. and T. Odean (2008). All that glitters: The effect of attention and news on the buying behavior of individual and institutional investors. Review of Financial Studies, 21, 785-818.

Bray, M. (1981). Futures trading, rational expectations, and the effcient markets hypothesis. Econometrica, 49, 575-596.

Cagan, P. (1981). Financial futures markets: is more regulation needed? Journal of Futures Markets, 1, 169-190.

Cohen, R.B., P.A. Gompers, and T. Vuolteenaho (2002). Who underreacts to cash flow news? Evidence from trading between individuals and institutions. Journal of Financial Economics, 66, 409-462.

Conrad, J. and G. Kaul (1988). Time-variation in expected returns. Journal of Business, 61, 409-425.

Cox, C.C. (1976). Futures trading and market information. Journal of Political Economy, 84, 1215-1237.

Danthine, J.-P. (1978). Information, futures prices, and stabilizing speculation. Journal of Economic Theory, 17, 79-98. 
Dueker, M.J. (1997). Markov switching in garch processes and mean-reverting stockmarket volatility. Journal of Business \& Economic Statistics, 15, 26-34.

Figlewski, S. (1981). GNMA passthrough securities, futures trading and volatility in the GNMA market. Journal of Finance, 36, 445-456.

Gelman, S. and B. Wilfling (2009). Markov-switching in target stocks during takeover bids. Journal of Empirical Finance, 16, 745-758.

Gray, S.F. (1996a). An analysis of conditional regime-switching models. Unpublished Working Paper, Fuqua School of Business, Duke University, Durham, NC.

Gray, S.F. (1996b). Modeling the conditional distribution of interest rates as a regimeswitching process. Journal of Financial Economics, 42, 27-62.

Gulen, H. and S. Mayhew (2000). Stock index futures trading and volatility in international equity markets. Journal of Futures Markets, 20, 661-685.

Hart, O.D. and D.M. Kreps (1986). Price destabilizing speculation. Journal of Political Economy, 94, 927-952.

Kaniel, R., G. Saar, and S. Titman (2008). Individual investor trading and stock returns. Journal of Finance, 63, 273-310.

Kurov, A. (2008). Tick size reduction, execution costs, and informational effciency in the regular and e-mini NASDAQ-100 index futures markets. Journal of Futures Markets, 28, 871-888.

Kyle, A.S. (1985). Continuous auctions and insider trading. Econometrica, 53, 13151336.

Lee, Y.-T., J.-C. Lin, and Y.-J. Liu (1999). Trading patterns of big versus small players in an emerging market: An empirical analysis. Journal of Banking and Finance, 23, 701-725.

Lo, A.W. and A.C. MacKinlay (1990). An econometric analysis of nonsynchronous trading. Journal of Econometrics, 45, 181-211. 
McKenzie, M.D., T.J. Brailsford, and R.W. Faff (2001). New insights into the impact of the introduction of futures trading on stock price volatility. Journal of Futures Markets, 21, 237-255.

McMillan, D.G. and R.Q. Garcia (2008). Effciency of the IBEX spot-futures basis: The impact of the mini-futures. Journal of Futures Markets, 28, 398-415.

Mech, T.S. (1993). Portfolio return autocorrelation. Journal of Financial Economics, $34,307-344$.

Powers, M.J. (1970). Does futures trading reduce price fluctuations in the cash markets? American Economic Review, 60, 460-464.

Sentana, E. and S. Wadhwani (1992). Feedback traders and stock return autocorrelations: Evidence from a century of daily data. Economic Journal, 102, 415-425.

Shiller, R.J. (1989). Market Volatility. Cambridge MA: MIT Press.

Stein, J.C. (1987). Informational externalities and welfare-reducing speculation. Journal of Political Economy, 95, 1123-1145.

Stoll, H.R. and R.E. Whaley (1988). Volatility and futures: Message versus messenger. Journal of Portfolio Management, 14, 20-22.

Wilfling, B. (2009). Volatility regime-switching in European exchange rates prior to monetary unification. Journal of International Money and Finance, 28, 240-270. 
Figure 1: Index futures contracts trading volume at the WSE

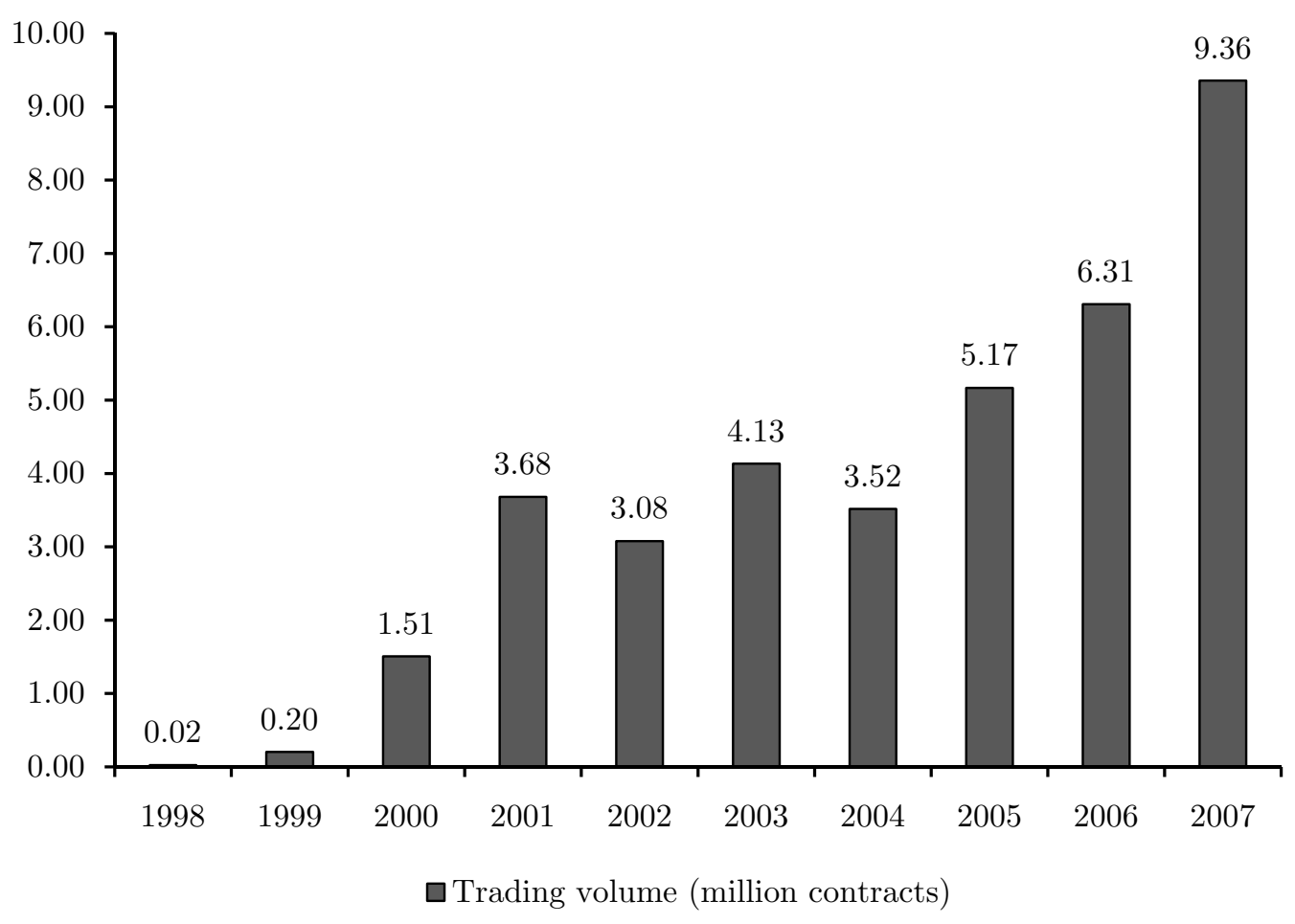


Figure 2: Annual percentage shares in trading turnover of different investor groups for WSE spot and futures markets

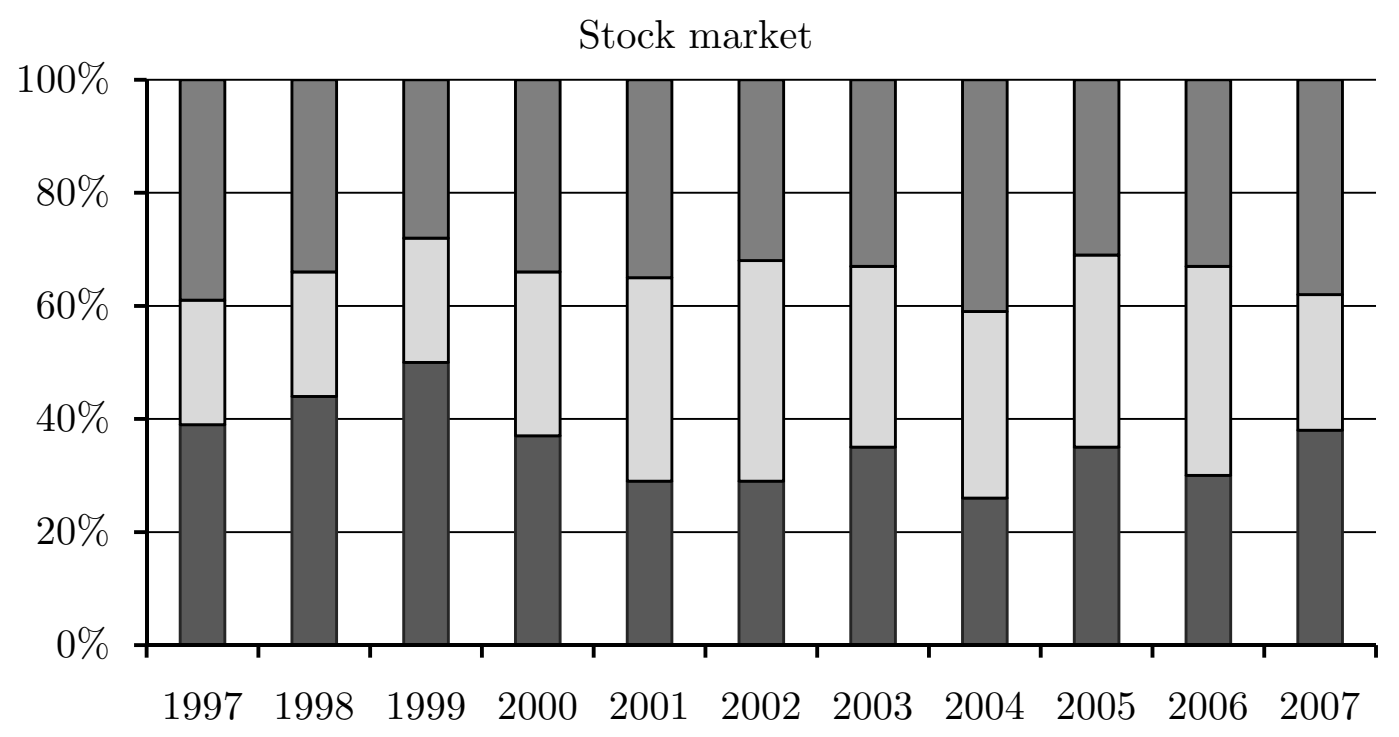

Futures market

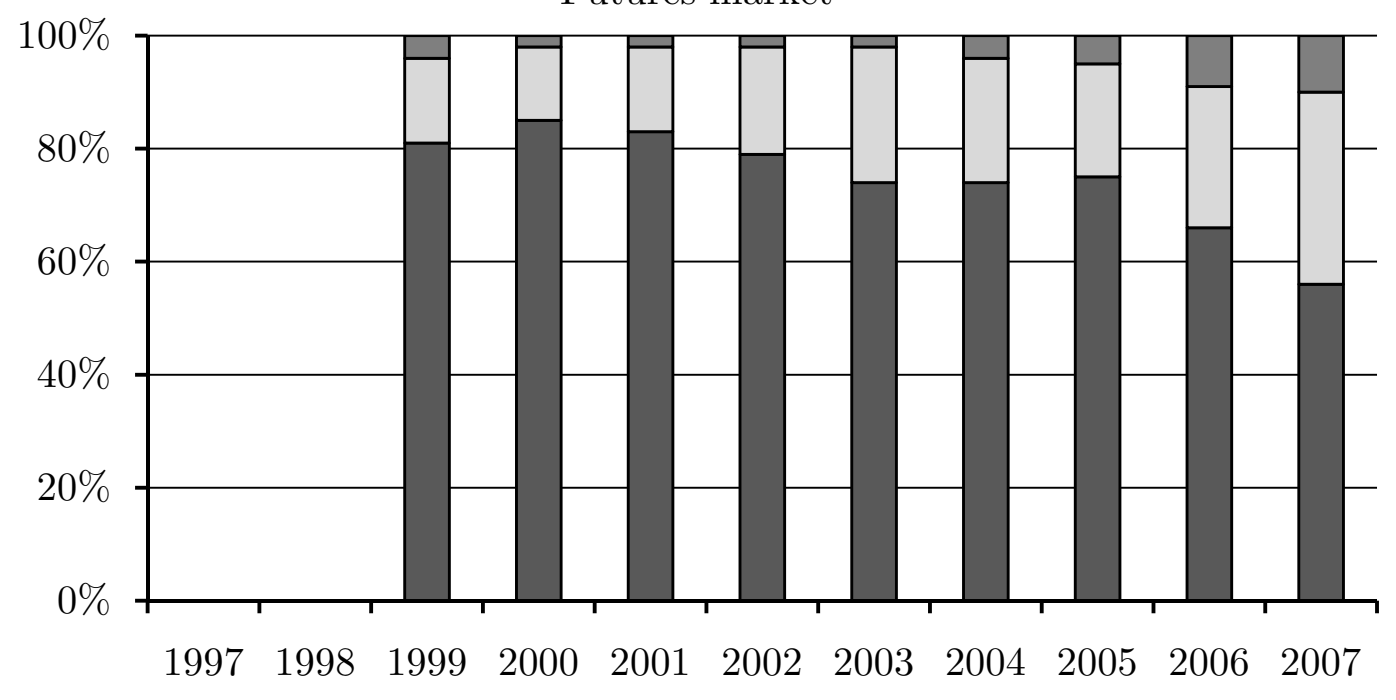

$\square$ Domestic individual $\quad \square$ Domestic institutional $\quad \square$ Foreign 
Figure 3: Regime-1 probabilities and conditional variances (WIG20)

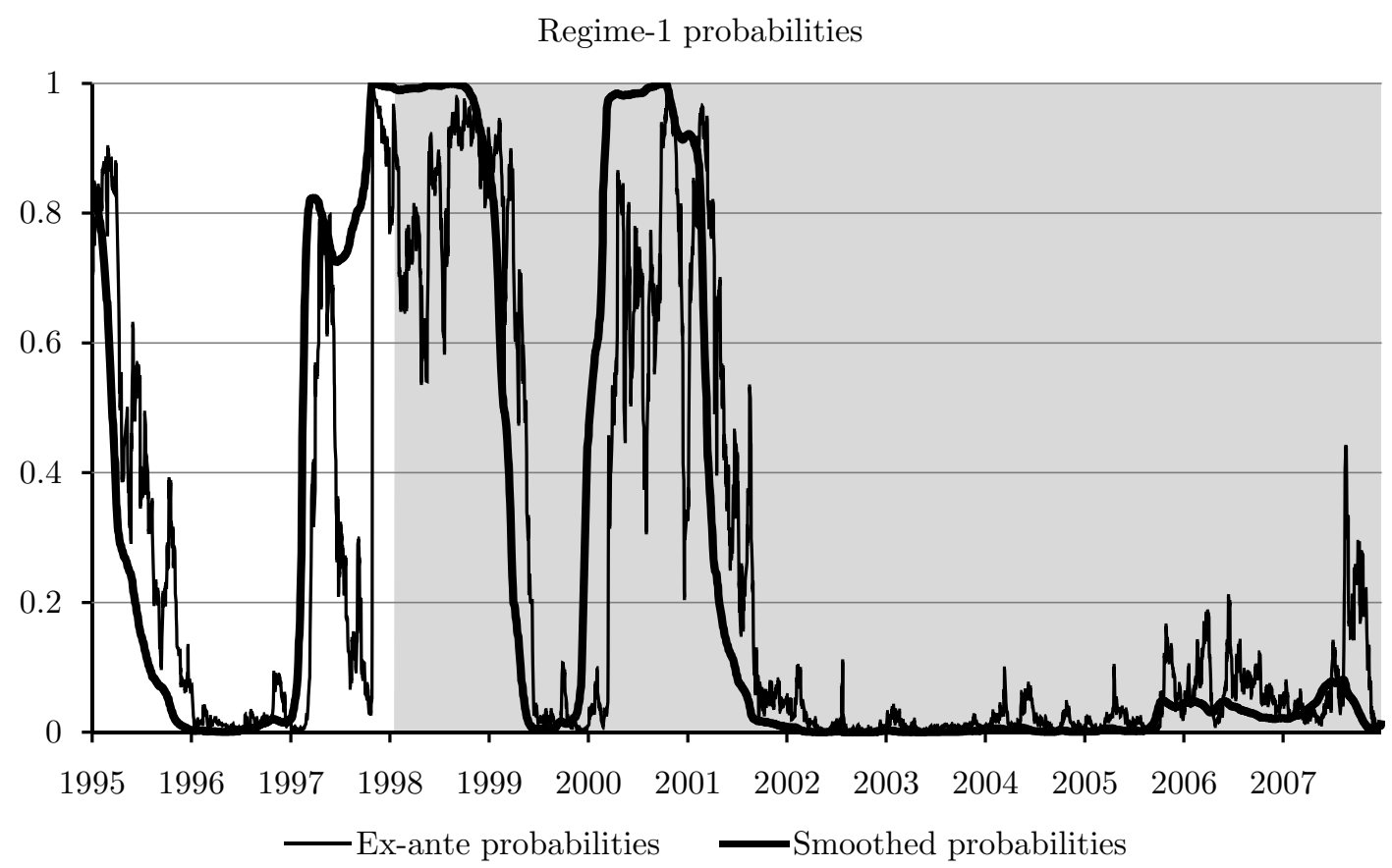

Conditional variances

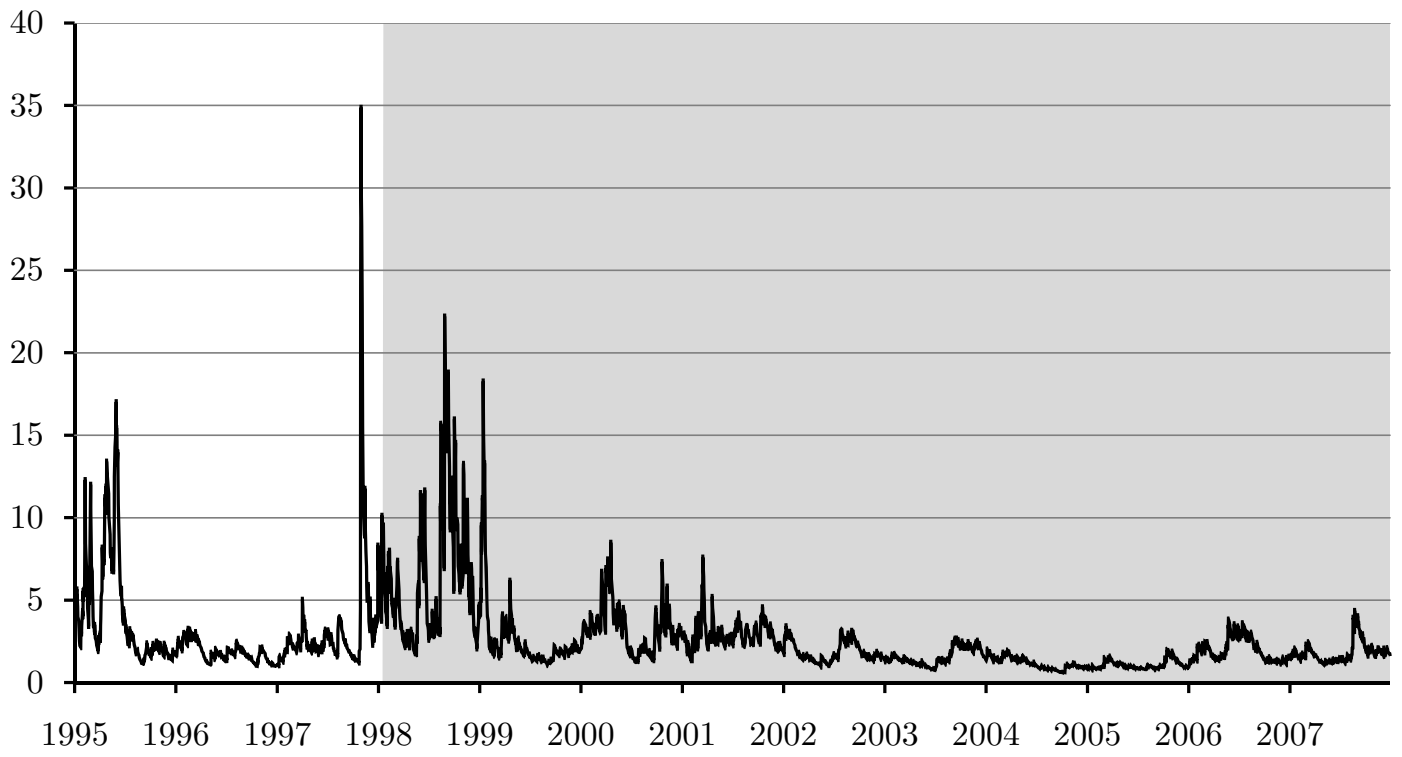


Figure 4: Regime-1 probabilities and conditional variances (TechWIG)

Regime-1 probabilities

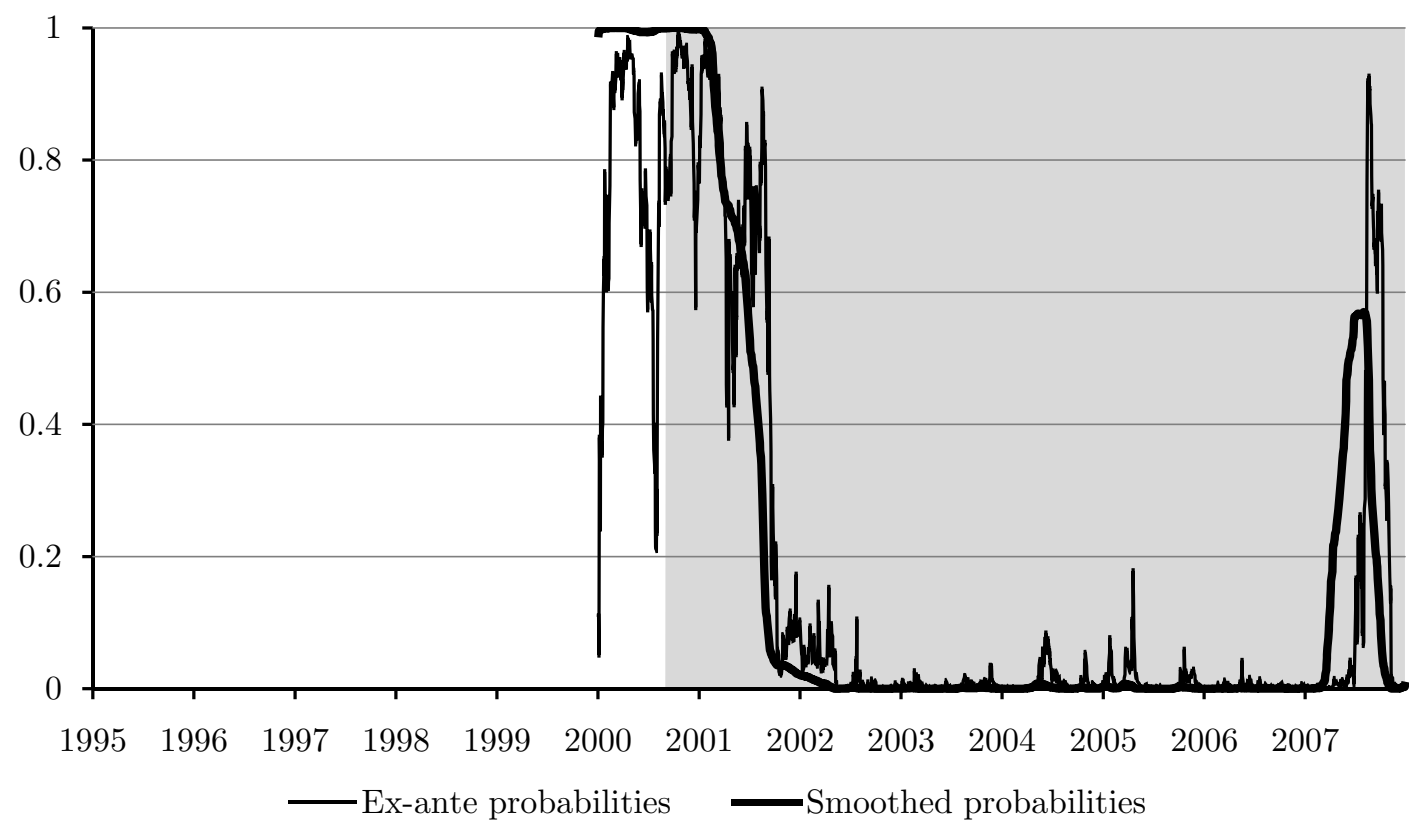

Conditional variances

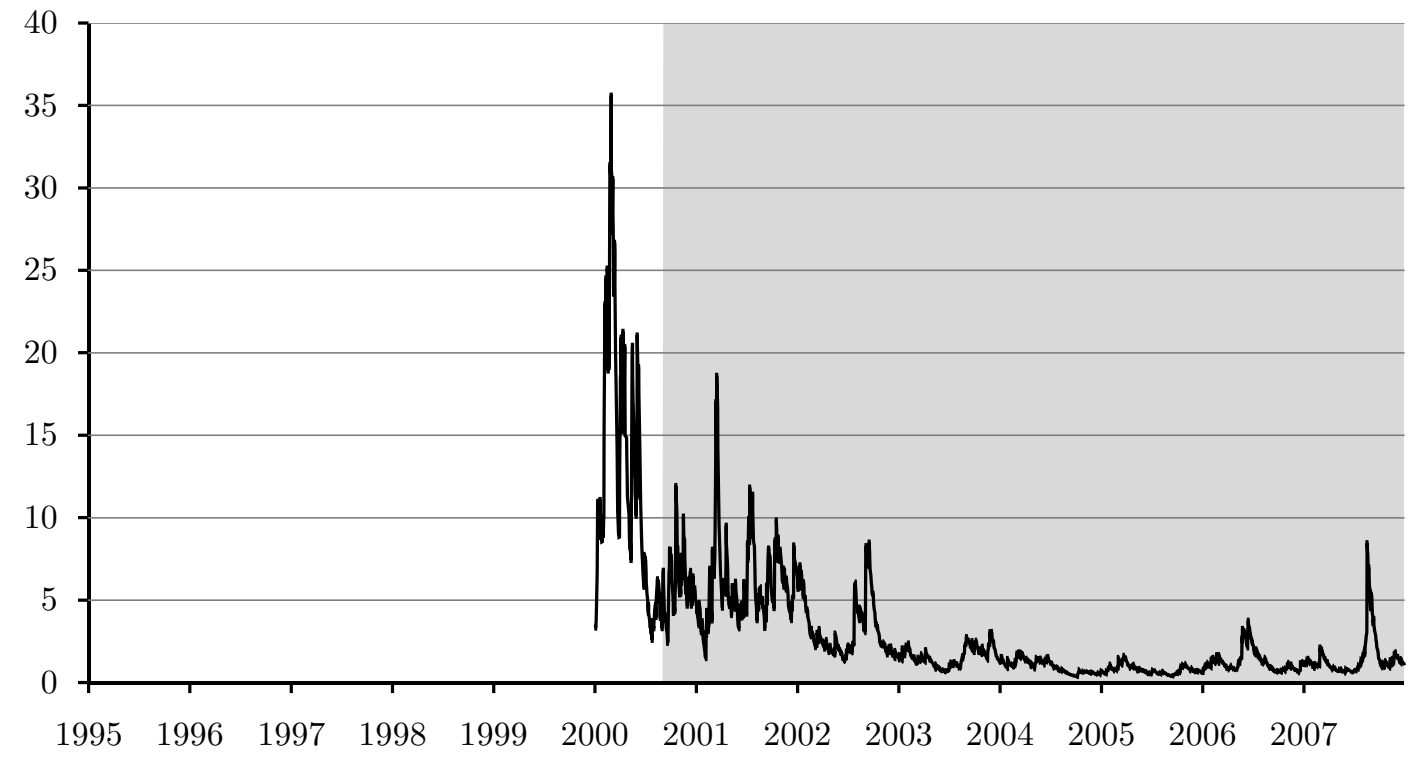


Figure 5: Regime-1 probabilities and conditional variances (mWIG40)

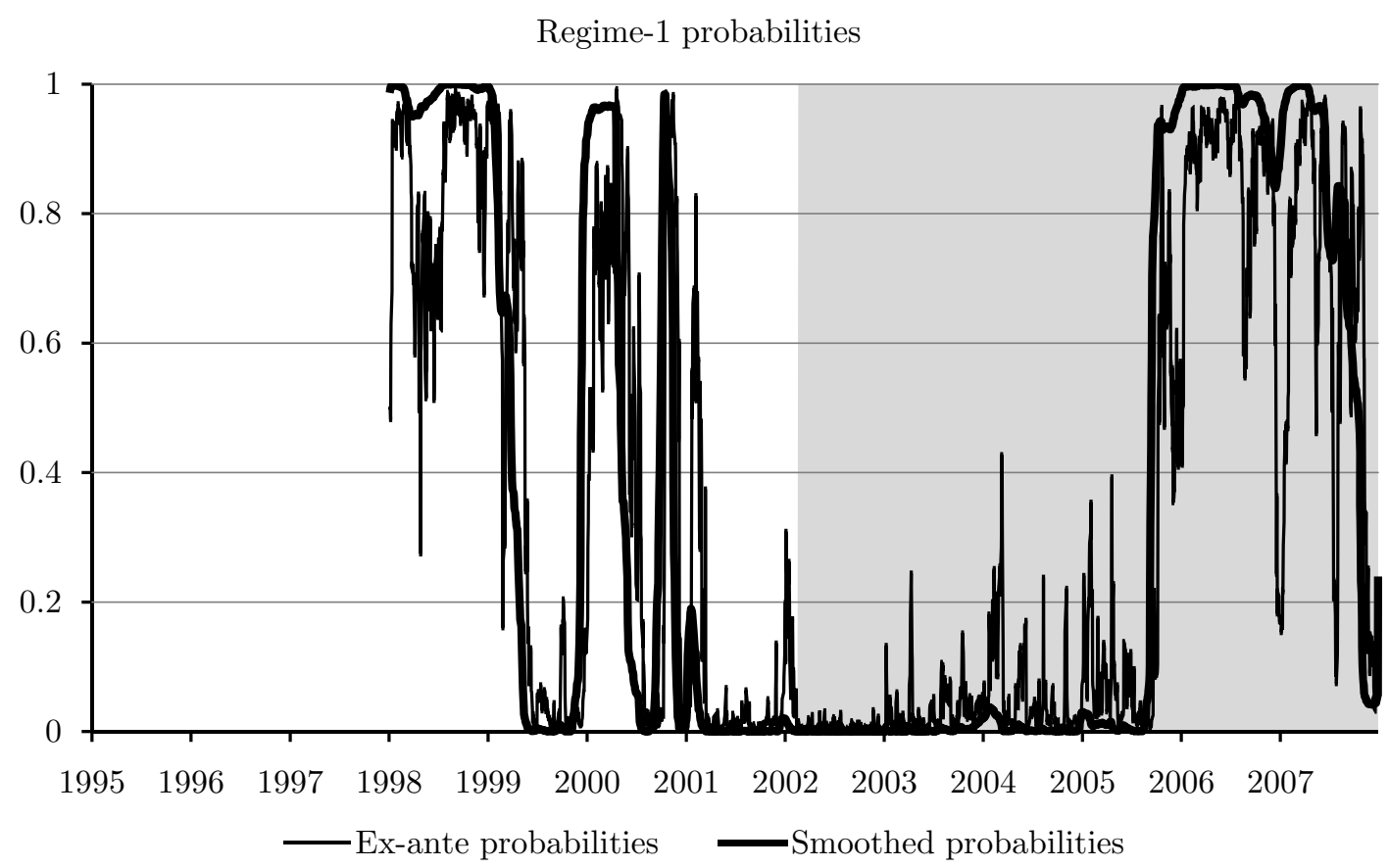

Conditional variances

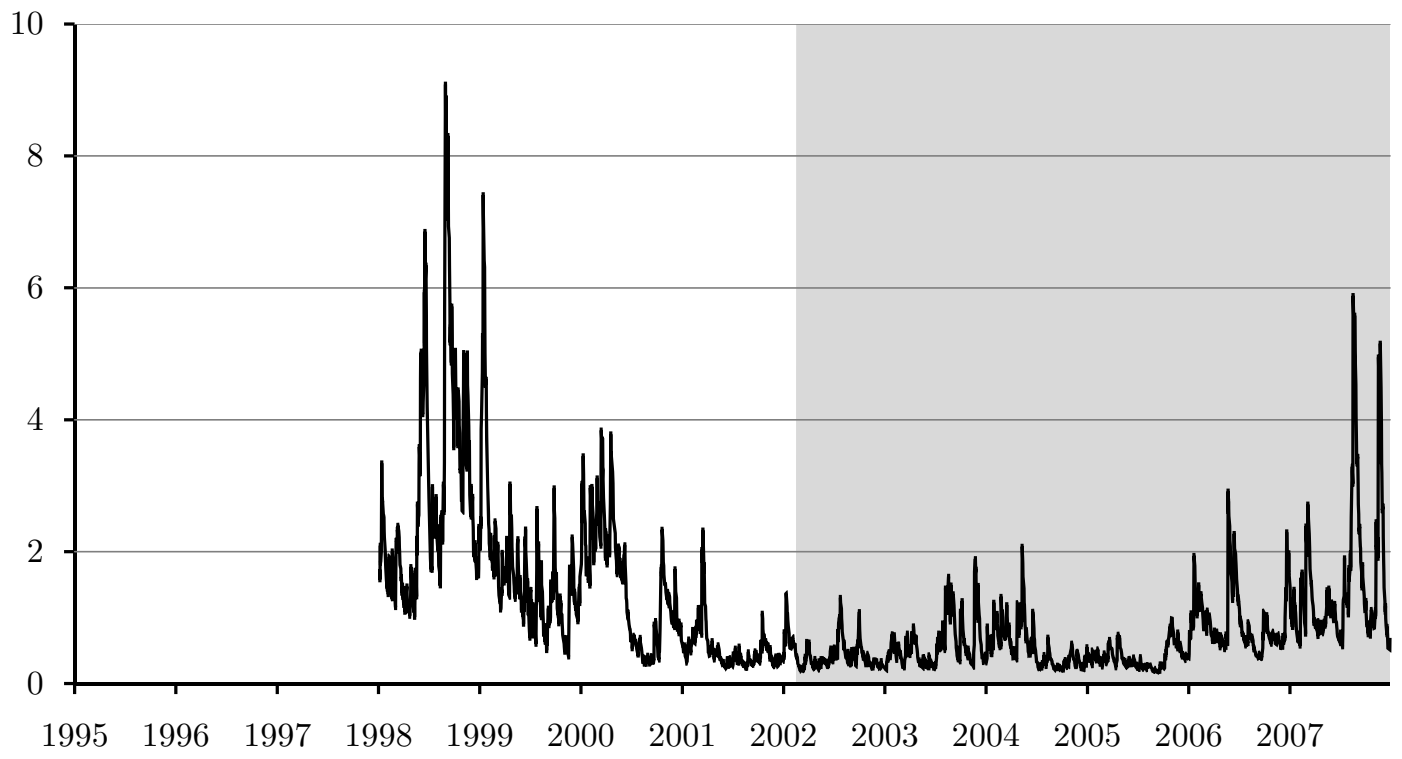


Figure 6: Regime-1 probabilities and conditional variances (WIG)

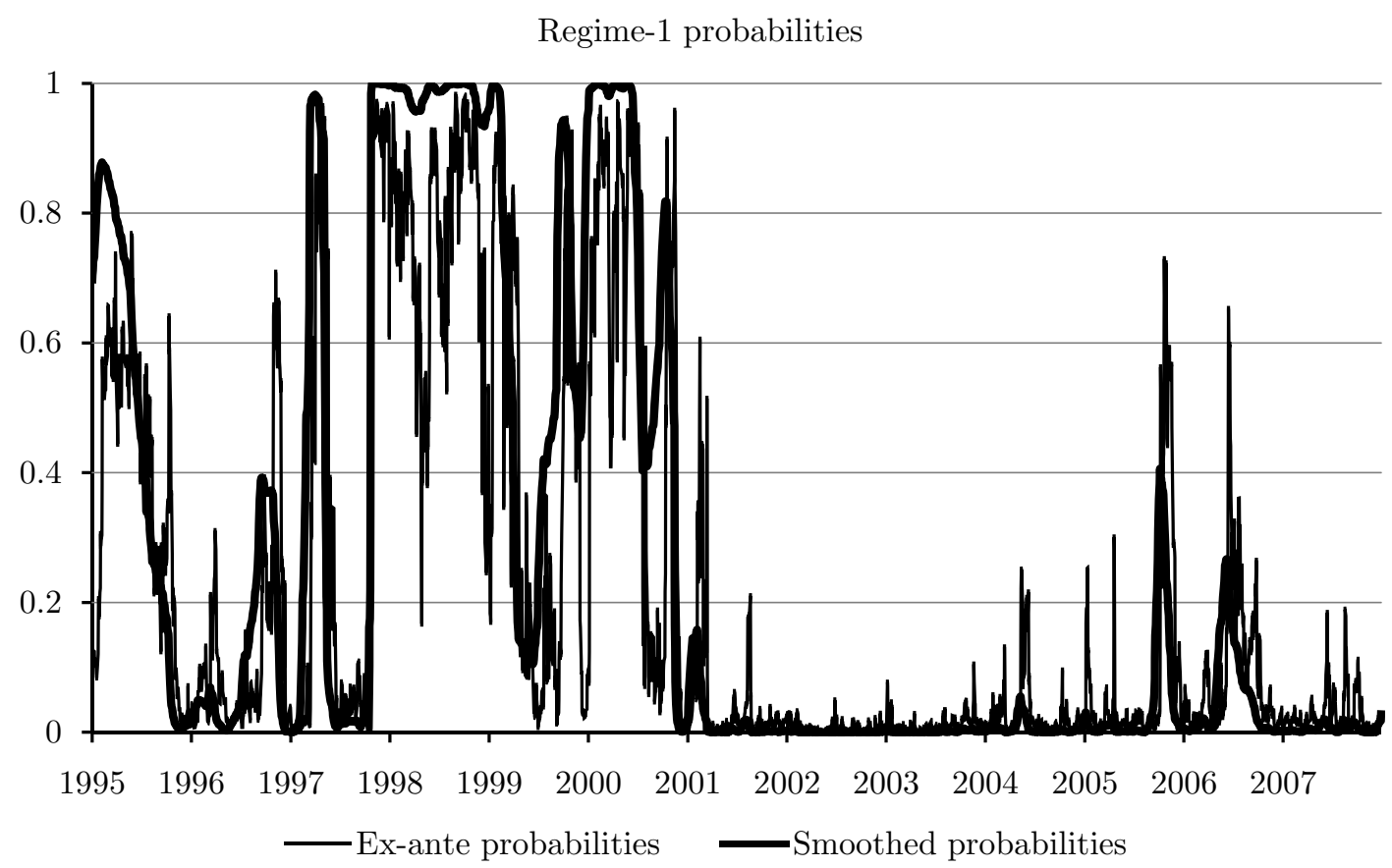

Conditional variances

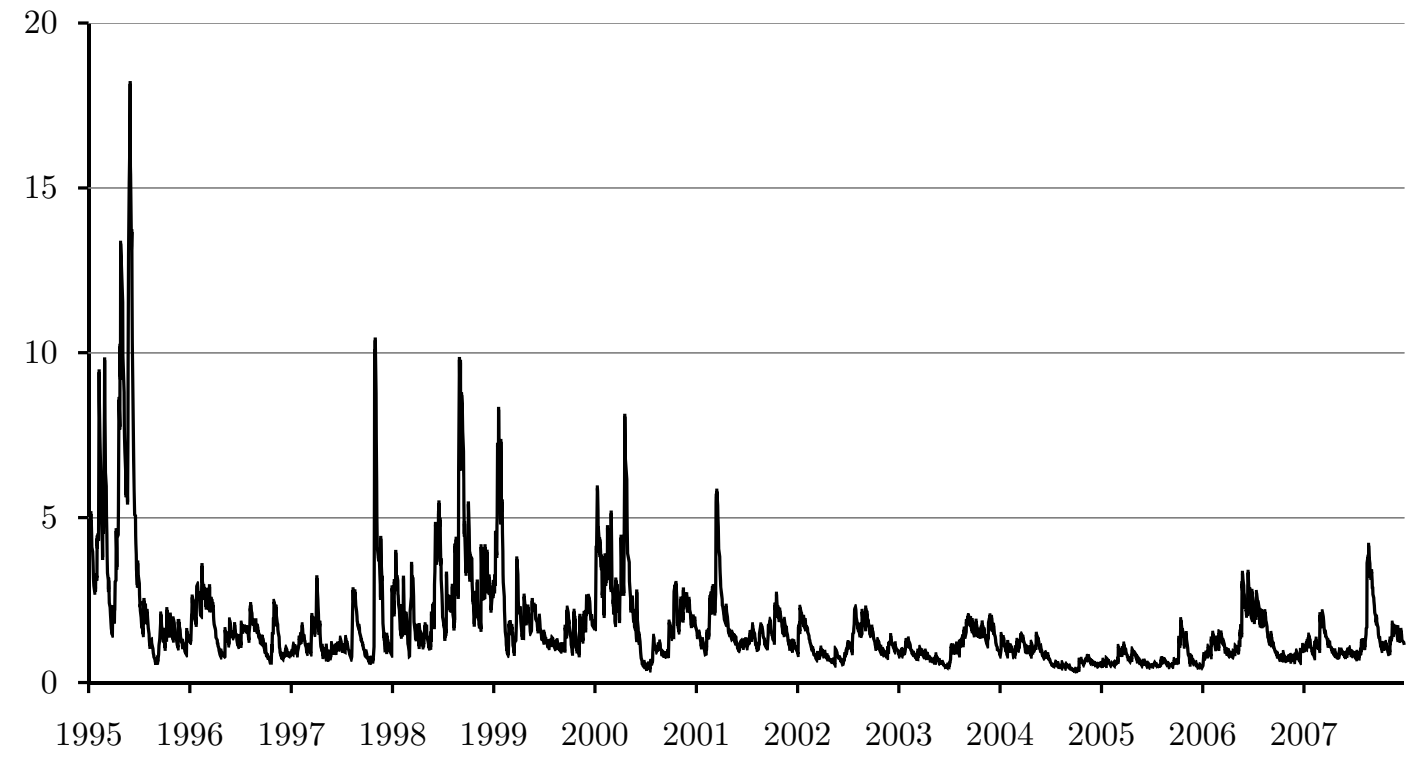


Figure 7: Regime-1 probabilities and conditional variances (sWIG80)

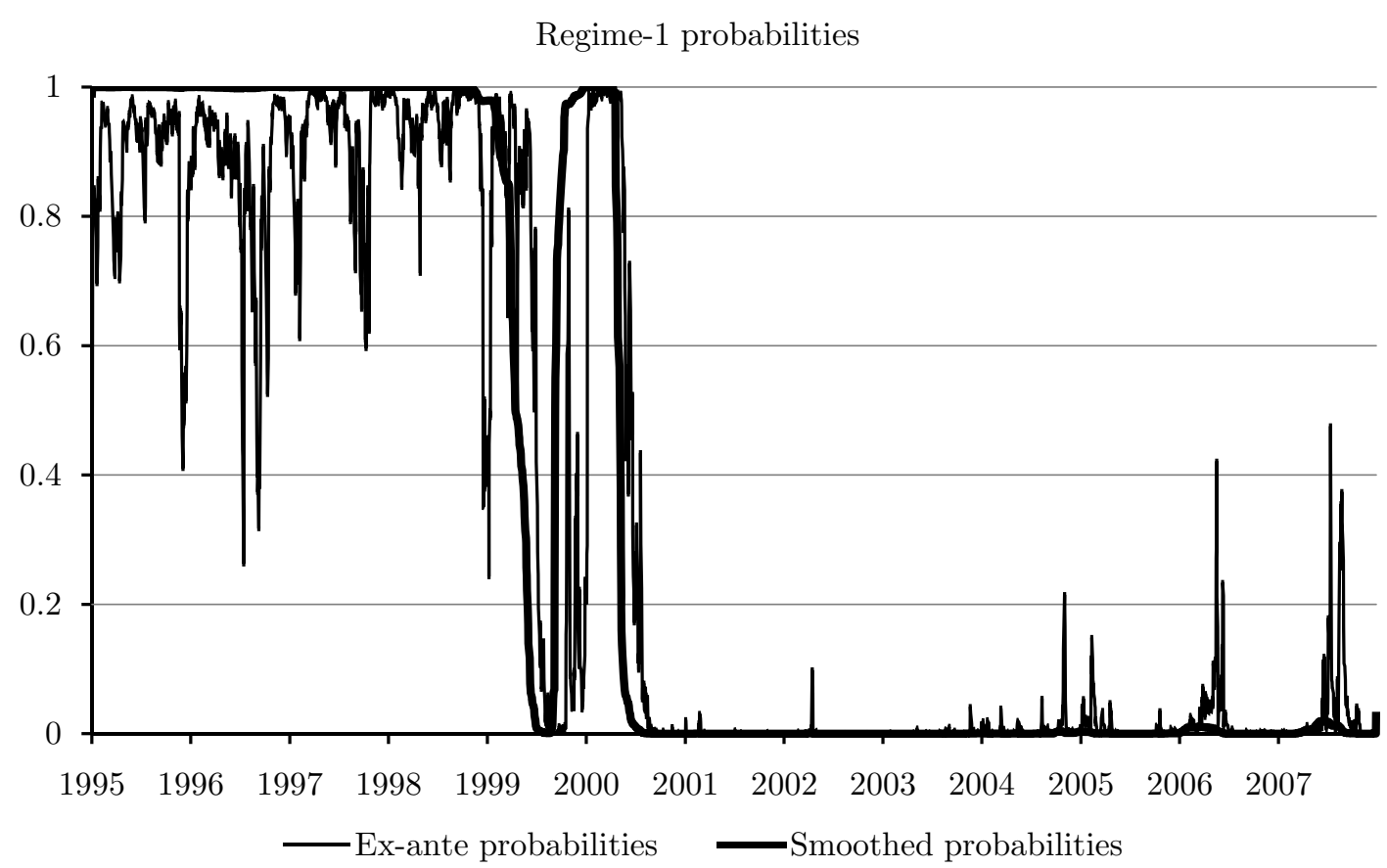

Conditional variances

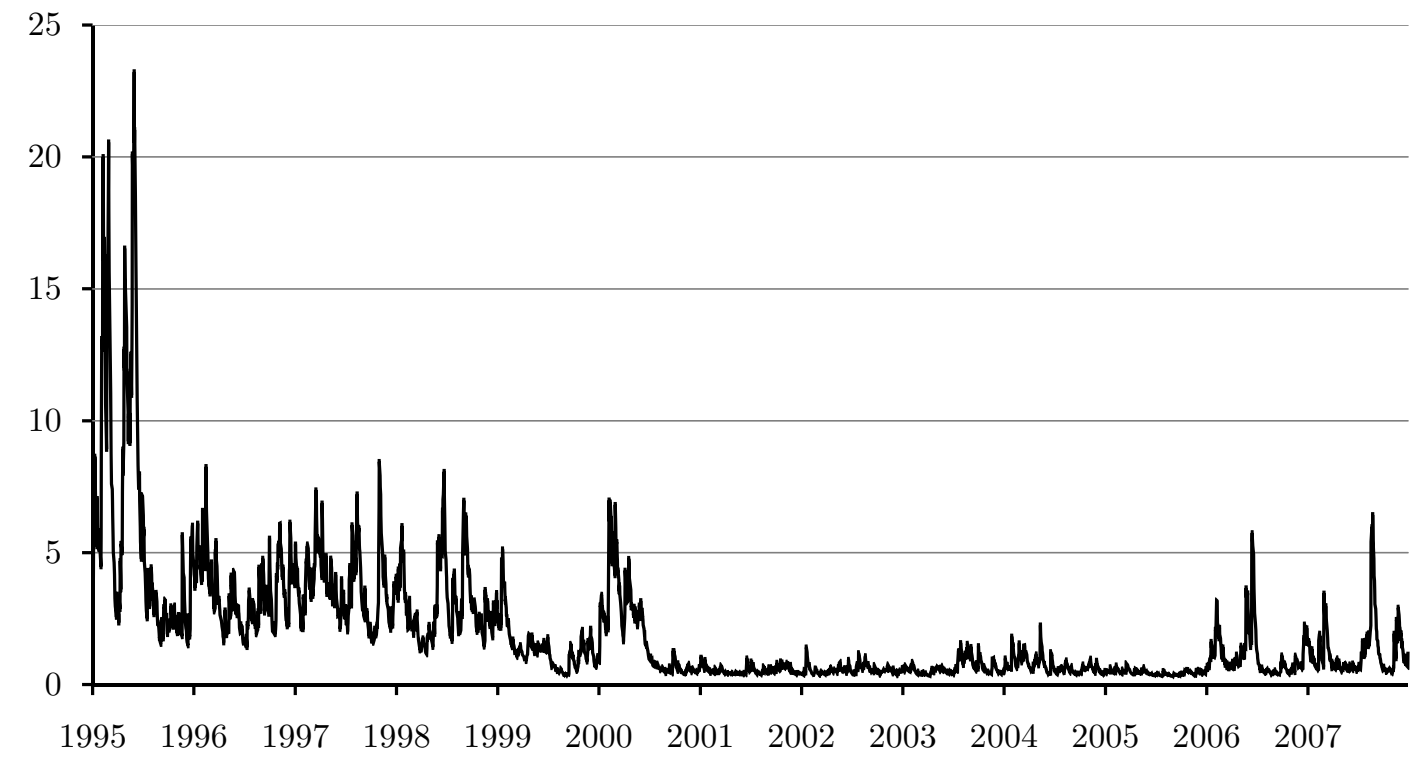


Table I: Estimates and related statistics for Markov-switching-GARCH model

\begin{tabular}{lllllll}
\hline & WIG20 & \multicolumn{3}{c}{ mWIG20 } & TechWIG \\
\cline { 2 - 7 } Parameters & Estimate & S. E. & Estimate & S. E. & Estimate & S. E. \\
\hline \hline Regime 1 & & & & & & \\
$a_{01}$ & -0.0713 & 0.0816 & $0.1744^{* * *}$ & 0.0381 & -0.111 & 0.0774 \\
$a_{11}$ & -0.0548 & 0.0340 & 0.0221 & 0.0301 & $-0.1113^{* * *}$ & 0.0373 \\
$a_{21}$ & $0.5502^{* * *}$ & 0.0525 & $0.5671^{* * *}$ & 0.0559 & $0.6795^{* * *}$ & 0.0607 \\
$b_{01}$ & $0.1885^{* *}$ & 0.0870 & 0.0262 & 0.0204 & 0.0402 & 0.1454 \\
$b_{11}$ & $0.1811^{* * *}$ & 0.0325 & $0.0878^{* *}$ & 0.0401 & $0.1419^{* * *}$ & 0.0616 \\
$b_{21}$ & $0.7789^{* * *}$ & 0.0358 & $0.8883^{* * *}$ & 0.0439 & $0.8521^{* * *}$ & 0.0549 \\
$q_{1}$ & $0.0960^{* * *}$ & 0.0252 & $0.1428^{* * *}$ & 0.0216 & 0.0477 & 0.0344 \\
{$\left[b_{11}\left(1-2 q_{1}\right)+b_{21}\right]$} & {$[0.9253]$} & & {$[0.9510]$} & & {$[0.9804]$} &
\end{tabular}

Regime 2

$\begin{array}{lllllll}a_{02} & 0.0658^{* *} & 0.0279 & 0.0353^{*} & 0.0193 & 0.0686^{* *} & 0.0301 \\ a_{12} & 0.0419^{* *} & 0.0199 & 0.1231^{* * *} & 0.0284 & 0.0440^{*} & 0.0225 \\ a_{22} & 0.2438^{* * *} & 0.0299 & 0.1211^{* * *} & 0.0176 & 0.2639^{* * *} & 0.0367 \\ b_{02} & 0.0237 & 0.0164 & 0.0268^{* * *} & 0.0091 & 0.0150^{* *} & 0.0069 \\ b_{12} & 0.0446^{* * *} & 0.0129 & 0.1412^{* * *} & 0.0271 & 0.0579^{* * *} & 0.0165 \\ b_{22} & 0.9386^{* * *} & 0.0302 & 0.8000^{* * *} & 0.0404 & 0.9299^{* * *} & 0.0174 \\ q_{2} & 0.1016^{* * *} & 0.0203 & 0.1040^{* * *} & 0.0198 & 0.1586^{* * *} & 0.0207 \\ {\left[b_{12}\left(1-2 q_{2}\right)+b_{22}\right]} & {[0.9741]} & & {[0.9118]} & & {[0.9695]} & \end{array}$

Transition probabilities

$\begin{array}{lllllll}\pi_{1} & 0.9958^{* * *} & 0.0025 & 0.9950^{* * *} & 0.0030 & 0.9954^{* * *} & 0.0031 \\ \pi_{2} & 0.9996^{* * *} & 0.0004 & 0.9980^{* * *} & 0.0012 & 0.9998^{* * *} & 0.0003\end{array}$

Log-likelihood

$-6249.4161$

$-3534.9395$

$-3789.1212$

\begin{tabular}{lllllll} 
Residual analysis & Estimate & p-value & Estimate & p-value & Estimate & p-value \\
\hline \hline$L B_{1}^{2}$ & $4.638^{* *}$ & $(0.031)$ & 0.189 & $(0.664)$ & 0.004 & $(0.985)$ \\
$L B_{2}^{2}$ & $4.639^{*}$ & $(0.098)$ & 0.893 & $(0.640)$ & 0.539 & $(0.764)$ \\
$L B_{3}^{2}$ & $7.266^{*}$ & $(0.064)$ & 0.915 & $(0.822)$ & 0.846 & $(0.838)$ \\
$L B_{5}^{2}$ & 7.563 & $(0.182)$ & 2.506 & $(0.776)$ & 3.459 & $(0.630)$ \\
$L B_{10}^{2}$ & 12.896 & $(0.230)$ & 4.731 & $(0.908)$ & 6.353 & $(0.785)$ \\
\hline
\end{tabular}

Notes: Estimates for the parameters from Eqs. (1) to (6). $L B_{i}^{2}$ denotes the Ljung-Box Q-statistics for serial correlation of the squared standardized residuals up to i lags. *, **, *** denote statistical significance at the $10 \%, 5 \%$ and $1 \%$ level, respectively. 